Revista Eletrônica do Mestrado

Profissional em Administração da UnP

\title{
edunp
}

V. 11, N. 1, 2019

ISSN 1984-4204

https://repositorio.unp.br/index.php/raunp

http://dx.doi.org/10.21714/raunp.v11i1.1909

\section{A percepção dos servidores universitários sobre a liderança na Universidade Federal de Santa Catarina}

\section{The perception of the university employees about the leadership at the Federal University of Santa Catarina}

\author{
Thiago Soares Nunes ${ }^{\mathrm{a}}$, Helen Fischer Günther ${ }^{\mathrm{b}}$ \\ a Pós-Doutorado em Administração. Centro Universitário UNA. adm.thiagosn@gmail.com \\ ${ }^{\text {b }}$ Doutora em Engenharia e Gestão do Conhecimento. Universidade do Sul de Santa Catarina. helen.fg@gmail.com
}

\begin{abstract}
Resumo
Percebe-se espaço existente na literatura para a discussão sobre quais são os elementos que levam à ocorrência da liderança no contexto do serviço público, considerando a ótica dos próprios servidores. Deste modo, o objetivo deste artigo é identificar referências e critérios de liderança dentro da Universidade Federal de Santa Catarina com base na percepção dos seus servidores docentes e técnico-administrativos. Metodologicamente, a pesquisa é caracterizada como qualitativa, descritiva e estudo de caso, com coleta de dados primários mediante questionário. As 214 respostas obtidas foram submetidas à análise de conteúdo e resultaram em três principais elementos para o reconhecimento da liderança na referida instituição: aspectos emocionais $(8,5 \%)$; hierárquicos $(31,7 \%)$ e, relevância do trabalho (59,8\%). Conclui-se que, independentemente de ser por uma questão hierárquica, um vínculo emocional ou relacionado ao trabalho desenvolvido, os líderes influenciam (negativamente ou positivamente) a cultura da instituição, alguns com maior poder de influência, outros na replicação dos valores e costumes estabelecidos ao longo da história.
\end{abstract}

Palavras-chave: Liderança; Setor público; Universidade; Servidor público federal; Gestão Universitária.

\begin{abstract}
Its noticed the existing gap in the literature for the discussion about which are the elements that lead to the occurrence of the leadership in the context of the public service, considering the perspective of the servers themselves. Thus, the objective of this article was to identify references and leadership criteria within the Federal University of Santa Catarina based on the perception of teachers and technical-administratives employees. Methodologically, the research is characterized as qualitative, descriptive and case study, with primary data collection through questionnaire. The 214 responses were submitted to content analysis and resulted in three main elements for the recognition of leadership in this institution: emotional aspects (8,5\%); hierarchical (31,7\%) and work relevance $(59,8 \%)$. It's concluded that, regardless of whether hierarchical, emotional or work related, leaders influence (negatively or positively) the institution's culture, some with greater influence, others in the replication of established values and behaviours throughout university history.
\end{abstract}

Keywords: Leadership; Public sector; University; Public federal servant; University Administration. 


\section{Introdução}

A ideia de liderança vai além da concepção de um traço inato (Robbins, 2005), perpassa a compreensão da liderança como um processo social que emerge das relações interpessoais entre os indivíduos na organização (Freitas Jr, Klein, \& Fargundes, 2015). Para os autores, embora as concepções mais recentes ampliem a compreensão da liderança, que extrapola o indivíduo-líder, estas não excluem do seu cerne o aspecto individual como importante.

No âmbito da administração pública, a liderança atua para mobilizar competências de seus dirigentes a fim de otimizar resultados organizacionais e se manifesta por meio de práticas específicas relacionadas a direcionamentos, dissolução de conflitos, avaliação de cenários e resultados, análise de riscos, criação e implementação de políticas, dentre outras (Brasil, 2014).

As instituições de ensino superior (IES) possuem diversas formas de manifestação da liderança e da distribuição do papel do líder, seja formal ou informal. O objetivo estabelecido tem como essência primar pelo sistema de ensino ao qual a instituição pertence, a gestão dos recursos para planejamento dos objetivos e garantir a qualidade da formação que oferta (Ortiz, 2017).

Logo, existem muitas dimensões percebidas pelos trabalhadores sobre aqueles que exercem funções de liderança dentro das universidades, podendo ser algo atribuído a um aspecto puramente hierárquico (vinculado ao cargo que ocupa), emocional (vínculo emocional com determinada pessoa) ou devido a relevância do trabalho desenvolvido pelo líder.

A motivação para este estudo advém em grande parte do espaço existente na literatura para a discussão acerca dos elementos que levam à ocorrência da liderança no contexto do serviço público, considerando a ótica dos próprios servidores que a vivenciam. Por isso, o objetivo desta pesquisa é identificar referências e critérios de liderança dentro da Universidade Federal de Santa Catarina (UFSC) com base na percepção dos seus servidores docentes e técnico-administrativos.

O interesse em estudar a liderança no contexto da UFSC, a partir da percepção dos seus servidores docentes e técnico-administrativos, parte da inquietação dos pesquisadores sobre como se formam e se moldam esses elementos na referida instituição. Tal percepção é importante para compreender o aspecto da liderança na UFSC, e ainda mais, aprofundar e observar como isso se manifesta dentro da própria cultura universitária. Logo, tem-se como referencial a liderança no setor público e, mais especificamente, a liderança em instituições públicas de ensino superior.

Este artigo está estruturado em cinco seções. A primeira seção consiste nesta introdução, que traz o contexto e o objeto de pesquisa, a motivação para o estudo e alguns conteúdos relacionados ao entendimento da temática em tela. A segunda seção traz o referencial teórico do estudo e aborda a liderança no setor público e a liderança nas instituições de ensino superior. A terceira seção relata os procedimentos adotados para o delineamento e execução da pesquisa de campo, assim como a quarta seção versa sobre o detalhamento da apresentação e análise dos resultados do estudo de caso. Ao final, na quinta seção, são apresentadas as principais conclusões e contribuições deste artigo, bem como sugestões para futuros trabalhos sobre o tema.

\section{Referencial Teórico}

Neste capítulo apresentam-se os temas que sustentaram a pesquisa, iniciando pela liderança no setor público, e em sequência, a liderança nas instituições de ensino superior. 


\subsection{Liderança no setor público}

O tema liderança na esfera pública desperta reações variadas, especialmente quando consideramos o espectro dos servidores públicos brasileiros. Isso se dá, voa de regra, porque há um temor de que se esteja falando de liderança carismática ou de importação de modismos, tais como os advindos dos Estados Unidos ou do setor privado (Amaral, 2006).

O que se percebe nesse estudo é que a pesquisa em liderança no Brasil obteve avanços e está relacionada com as instituições de ensino superior, mas ainda é considerada escassa e defasada quando se considera especificamente o contexto da administração pública (Fonseca; Porto; Borges-Andrade, 2015). Bertoncini e Cunha (2017) identificaram como temas mais estudados na área: competências do líder no setor público brasileiro; recompensas do líder-liderado no setor público; dificuldades para o exercício da liderança no setor público brasileiro; aprendizagem no desenvolvimento de competências de liderança; e liderança e cultura organizacional no setor público brasileiro.

Falar em governança das instituições públicas brasileiras também é falar em liderança, uma vez que "é fundamental mobilizar conhecimentos, habilidades e atitudes dos dirigentes em prol da otimização dos resultados organizacionais" (Brasil, 2014, p. 40). O modelo de liderança organizacional pública brasileira, também denominado de sistema de liderança, fundamentalmente está relacionado à aplicação dos princípios de coordenação, delegação de competência e governança que é adotado (Brasil, 2014). Segundo esse referencial, são consideradas práticas relacionadas à liderança organizacional:

a) Avaliar, direcionar e monitorar a gestão da organização, especialmente quanto ao alcance de metas organizacionais.

b) Responsabilizar-se pelo estabelecimento de políticas e diretrizes para a gestão da organização e pelo alcance dos resultados previstos.

c) Assegurar, por meio de política de delegação e reserva de poderes, a capacidade das instâncias internas de governança de avaliar, direcionar e monitorar a organização.

d) Responsabilizar-se pela gestão de riscos e controle interno.

e) Avaliar os resultados das atividades de controle e dos trabalhos de auditoria e, se necessário, determinar que sejam adotadas providências.

Assim, a liderança contribui com a efetividade da organização pública ao trazer um conjunto de práticas que dá subsídio às ações e aos projetos da instituição, além de estabelecer e fazer cumprir parâmetros de qualidade e de lisura para os resultados a serem alcançados.

É preciso considerar que há distintas realidades dentro da administração pública brasileira. Há quadros funcionais heterogêneos, diferenças culturais e entre as gerações, conflitos e dificuldade de cooperação e de continuidade (Amaral, 2006). Por isso é que lideranças acabam se destacando quando apresentam características como escuta, comunicação, capacidade de adaptação, de reflexão e de estímulo ao aprendizado, bem como o direcionamento à formação de consensos e à negociação, a serem observadas na análise do caso em estudo (seção 4 deste artigo).

Além disso, espera-se que o líder possua a capacidade de compreender os desafios e as adversidades que são colocadas pela realidade nacional, de lidar com a complexidade das decisões públicas, de enfrentar as diferenças e incorporar a diversidade, de praticar a boa governança e de contribuir para as necessárias 
reformas (Amaral, 2006).

Fleury e Fleury (2004) explanam que o líder sabe agir de modo responsável e reconhecido, uma vez que liderança que implica ações como mobilizar, integrar, transferir conhecimentos, recursos, habilidades, que agreguem valores econômicos à organização e valor social ao indivíduo.

Liderar no setor público, portanto, refere-se ao conjunto de práticas, seja de natureza humana, seja de natureza comportamental, que assegura as condições para o exercício da governança efetiva, isto é, pessoas íntegras, capacitadas, competentes, responsáveis e motivadas ocupando os principais cargos das organizações e liderando os processos de trabalho (Brasil, 2014).

\subsection{Liderança nas Instituições de Ensino Superior}

Não há consenso entre os estudiosos sobre o conceito de liderança no contexto do ensino superior, uma vez que alguns autores enfatizam algumas características particulares sobre as percepções que coletam em seus estudos, e outros as diferenciam a partir das perspectivas teóricas que influenciam sua conceituação (Ortiz, 2017).

O presente e o futuro das instituições de ensino superior estão relacionados diretamente com a qualidade de sua liderança e do compromisso com alguns valores específicos, tais como a meritocracia, que deve permear todos os setores da universidade (Altbach \& Salmi, 2011).

A liderança em instituições de ensino é concebida de diferentes maneiras, as atribuições podem ser consideradas sob o ponto de vista formal e funcional do papel do líder, em que é atribuída ao gestor a responsabilidade da administração dos recursos, o desenvolvimento de planos em resposta a objetivos estabelecidos pelo sistema de ensino, além de garantir a qualidade nos processos de formação - que é a razão de ser das instituições de ensino, mas que muitas vezes é o aspecto que menos recebe pelos gestores (Ortiz, 2017).

Reis (2010) evidencia que, no Brasil, ainda faltam líderes no campo da gestão universitária; alguns poucos líderes efetivamente investem na aprendizagem pessoal. O que se vê é que, de modo geral, observa-se o que acontece no dia a dia e, quando muito, direciona-se o pensamento para o amanhã. Na liderança, precisase desenvolver uma visão de médio e de longo prazo e, nas universidades públicas federais, ainda faltam gestores adequadamente preparados.

Neste aspecto, em pesquisa desenvolvida por Nunes, Tolfo e Garcia (2018) sobre os valores organizacionais em uma Universidade Federal, os autores observaram, pelos discursos dos docentes e técnicosadministrativos, diversos valores praticados que não estão em consonância com os valores declarados. Os valores estão ligados de forma direta ou indireta ao papel dos líderes organizacionais

Por exemplo, os valores "bem administrada e planejada" (uma instituição com estratégias eficientes e efetivas de gestão e de busca dos recursos para a realização de suas metas) e "saudável" (uma instituição saudável, ancorada na concepção de que a saúde é construída e vivida pelas pessoas em seu ambiente cotidiano, contribuindo para uma formação integral e maior qualidade de vida) foram constatados como não praticados pelos participantes da pesquisa com $81,8 \%$ e $74,3 \%$ respectivamente. Para os autores existe uma má gestão por parte dos líderes, motivada principalmente pelo corporativismo existente dentro da universidade, além do clima de impunidade, grupos dominantes e outros traços culturais presente na realidade brasileira e do serviço público.

Em outra pesquisa sobre a cultura organizacional em uma universidade, Nunes (2016) identificou 
que muitos líderes não têm conhecimento sobre as práticas e funções dos seus liderados, algumas vezes tem noção de suas responsabilidades e também dificuldades em gerir pessoas. Concomitantemente, Freitas Jr et al. (2015) ressaltam a importância do líder saber se relacionar com seus liderados, e destacam alguns aspectos fundamentais para manter esse bom relacionamento, como a ética, respeito, habilidade de comunicação, saber escutar e demais.

Sabe-se que a importância do líder no êxito das instituições de ensino superior advém do alto nível de influência que possuem na organização e nos grupos sociais a ela relacionados e devem ser relacionadas às peculiaridades dessas organizações $($ Ortiz, 2017) e, geralmente a liderança é vista como uma solução para quase todos os problemas (Bolman \& Deal, 1995).

Lorenzo (2005) elucida que atualmente se busca sintetizar as teorias focadas nas qualidades dos indivíduos (líderes) com as teorias focadas no contexto (liderança), resultando na perspectiva de que a liderança é um fenômeno que combina certas características da pessoa e da situação em consonância com um objetivo compartilhado. Assim, o autor propõe que a liderança é uma integração entre o indivíduo, o contexto, o grupo e o objetivo. Lorenzo (2005) ainda elenca estas características para a liderança:

a) função inerente ao grupo e, por extensão, à toda a instituição. É por isso que mais e mais pessoas falam sobre liderança e menos sobre líder;

b) é uma função pertencente ao grupo, não a uma pessoa e menos ainda a uma posição no organograma;

c) está inserida na cultura da instituição, representa um dos valores que constituem a cultura da organização;

d) é uma atividade que envolve o domínio de processos de natureza tripla: técnica, interpretativa e transformadora;

e) é uma função também compartilhada;

f) é exercida de maneira colegiada e colaborativa.

É premente considerar que as instituições de ensino superior apresentam diferenças substanciais em relação às instituições de ensino de outros níveis, pois possuem um alto grau de especialização do corpo docente, uma orientação para a formação de profissionais de diversas áreas, desenvolvimento de atividades de ensino, vinculação, pesquisa e desenvolvimento tecnológico. Ademais, estão imersas em um contexto dinâmico que requer adaptação às mudanças que ocorrem em ambientes internacionais e locais (Ortiz, 2017).

Não obstante, a liderança é considerada como fortemente influenciadora de eficácia e melhoria das instituições de ensino, tornando-se uma prioridade nos programas de políticas educacionais da Organização para Cooperação e Desenvolvimento Econômico (OCDE) e seus países membros. Considera-se, então, que a liderança é essencial para alcançar uma melhor gestão nas instituições de ensino superior e pode ser considerada tanto uma estratégia e quanto uma competência necessária aos dirigentes educacionais (Romero; Cázares; Barrera, 2017).

Consequentemente, Daft (1999) esclarece que a liderança envolve influência no comportamento do outro ou do grupo, tanto para reforçar quanto modificar, com vistas ao alcance de objetivos, sejam estes individuais, pessoais ou organizacionais. Além disso, tal influência provém da própria estrutura organizacional (influência formal), mas também das relações informais. 


\section{Método}

Para alcançar o objetivo proposto, utilizou-se a abordagem qualitativa. Nesta abordagem procura-se compreender os significados e características situacionais apresentadas pelos participantes, as quais expressam um universo de significados, motivos, aspirações e valores que correspondem a um aspecto mais profundo das relações, processos e fenômenos (Minayo, 1994; Richardson, 2008). Ou seja, justifica-se esta abordagem pois ela expressa um conjunto de aspectos subjetivos e de significados que não podem ser quantificados.

Portanto, ao tentar compreender o fenômeno por meio da interpretação e consciência do indivíduo, a qual é subjetiva, a pesquisa está inserida no paradigma interpretativista (Burrel \& Morgan, 1979). Por este paradigma, é possível priorizar a percepção e significados que os participantes da pesquisa apresentam em relação ao fenômeno observado e vivenciados por eles no ambiente pesquisado. Tal paradigma se encontra cada vez mais presente nos estudos organizacionais brasileiros, relacionado a temas como cultura, identidade, relações de poder e demais (Vergara \& Caldas, 2005).

Ademais, a pesquisa também se classifica como descritiva, uma vez que descreve a percepção dos servidores docentes e técnico-administrativos sobre as pessoas representativas para eles na Universidade, e também como estudo de caso. O estudo ocorreu na Universidade Federal de Santa Catarina, que durante a pesquisa apresentava aproximadamente 5.710 servidores (2.540 docentes e 3.170 técnicos-administrativos).

Quanto à amostra da pesquisa, os pesquisadores optaram por não realizar a mesma, uma vez que tiveram acesso à população. O questionário utilizado foi encaminhado para o e-mail institucional de todos os participantes, divulgado também pelo setor de comunicação de pesquisas da universidade e por alguns servidores de forma voluntária. Ao total, foram respondidos 214 questionários.

O instrumento utilizado na coleta dos dados, questionário online, apresentou perguntas abertas e fechadas sobre o participante (dados sociodemográficos e relacionado ao trabalho/cargo), bem como questionamentos sobre o fenômeno pesquisado - o servidor importante/representativo para ele e o porquê da escolha. Ressaltase que o instrumento em questão apresentava outros questionamentos, uma vez que era parte de uma pesquisa mais ampla.

Com relação à interpretação e análise dos dados, após coletados, os mesmos foram filtrados e categorizados. Tendo como principalmente ferramenta para tal a análise de conteúdo de Bardin (2011), a qual segue a pré-análise, exploração do material e tratamento dos resultados, e por fim, a inferência e interpretação das informações. Com base nas respostas dos participantes e relacionando estas com a literatura sobre liderança, foram identificadas três categorias que deram base para as análises da pesquisa.

\section{Quadro 1}

Categoria e subcategorias de análise

\begin{tabular}{|c|c|}
\hline DIMENSÃO & CATEGORIAS \\
\hline \multirow{2}{*}{ Liderança } & Posição Hierárquica \\
\cline { 2 - 2 } $\begin{array}{c}\text { (Compreende as pessoas significantes para a organização, as quais reforçam os valores da } \\
\text { cultura, representam o que a organização defende, estabelecem padrões de desempenho, e } \\
\text { motivam os integrantes da organização) }\end{array}$ & Relação emocional \\
\cline { 2 - 3 } & Relevância do trabalho \\
\hline
\end{tabular}

Fonte: Elaborado pelos autores.

Ressalta-se que todos os aspectos éticos foram seguidos para a realização da pesquisa e, consequentemente, proteção e anonimato dos participantes, tal qual como regula a Resolução $n^{\circ} 466$, de 12 
de dezembro de 2012, do Conselho Nacional de Saúde - CNS (Brasil, 2012). Assim, os participantes foram nomeados com a letra "P" e seus respectivos números, de 1 a 214.

\section{Análise e discussões dos resultados}

AUniversidade Federal de Santa Catarina (UFSC) foi criada em 18 de dezembro de 1960 mediante a Lei $\mathrm{n}^{\mathrm{o}} 3.849$, pelo então presidente da República Juscelino Kubitschek. Desde então observa-se uma hegemonia e alternância de poder entre alguns centros de ensino (Centro de Ciências Jurídicas - CCJ; Centro de Tecnologia - CTC; Centro de Ciências da Saúde - CCS) como pode ser observado no Quadro 2, a seguir. Ressalta-se que referido quadro apresenta informações até 2016, período final da pesquisa desenvolvida. Não obstante, as 2 gestões seguintes seguiram com docentes vinculados ao Centro de Ciências Jurídicas (CCJ): 2016-2017 com Luiz Carlos Cancellier de Olivo e 2018-2022 com Ubaldo Cesar Balthazar.

\section{Quadro 2}

Reitores da UFSC (até 2016)

\begin{tabular}{|c|c|c|}
\hline GESTÃO & REITOR & CENTRO \\
\hline $1961-1972$ & João David Ferreira Lima & CCJ \\
\hline $1972-1976$ & Roberto Mündel de Lacerda & CCJ \\
\hline $1976-1980$ & Caspar Erich Stemmer & CTC \\
\hline $1980-1984$ & Ernani Bayer & CCJ \\
\hline $1984-1988$ & Rodolfo Joaquim Pinto da Luz & CCJ \\
\hline $1988-1992$ & Bruno Rodolfo Schlemper Jr. & CCS \\
\hline $1992-1996$ & Antônio Diomário de Queiroz & CTC \\
\hline $1996-2000$ & Rodolfo Joaquim Pinto da Luz & CCJ \\
\hline $2000-2004$ & Rodolfo Joaquim Pinto da Luz & CCJ \\
\hline $2004-2008$ & Lúcio José Botelho & CCS \\
\hline $2008-2012$ & Álvaro Toubes Prata & CTC \\
\hline $2012-2016$ & Roselane Neckel & CFH \\
\hline
\end{tabular}

Fonte: Elaborado pelos autores.

Os participantes da pesquisa foram os servidores docentes e técnico-administrativos da UFSC. Desta forma, a Tabela 1, a seguir, apresenta resumidamente as principais características do público pesquisado.

Tabela 1

Descrição dos participantes da pesquisa

\begin{tabular}{lcc}
\hline \multicolumn{1}{c}{ Dados dos Participantes } & Frequência absoluta & Frequência Relativa \\
\hline Sexo: Feminino & 114 & 53,3 \\
Sexo: Masculino & 99 & 46,3 \\
Idade média: 40 anos & - & - \\
Estado Civil: Casado(a)/União Estável & 147 & 68,7 \\
Última formação completa: Pós-Graduação - Doutorado & 91 & 42,6 \\
Vínculo: Servidor Técnico-Administrativo & 116 & 54,2 \\
Vínculo: Servidor Docente & 98 & 45,8 \\
Tempo de trabalho na UFSC: de 1 a 5 anos & 106 & 49,5 \\
Regime de trabalho: 40 horas & 109 & 50,9 \\
Lotação (Campus): Florianópolis & 195 & 91,1 \\
Lotação: Centro de Ensino & 131 & 61,2 \\
Cargo de direção ou função gratificada: Não & 173 & 80,8 \\
\hline
\end{tabular}


Fonte: Elaborado pelos autores.

Foi questionado aos participantes sobre as pessoas que eles consideram importantes ou significativas para a UFSC e o porquê de sua escolha. Compreende-se que as pessoas significantes para a organização, reforçam os valores da cultura, representam o que a organização defende, estabelecem padrões de desempenho, e motivam os integrantes da organização.

A partir de análise dos dados coletados nas questões abertas, foram identificados três categorias que caracterizam as percepções dos entrevistados: a) hierárquico (importância referente ao cargo ou posição hierárquica ocupada pela pessoa); b) relação emocional (importância devido a um vínculo emocional); c) trabalho que a pessoa exerceu ou exerce na instituição (importância do trabalho realizado pela pessoa ou sua relevância social para o pesquisado). Sobre as incidências destes nas respostas, foi detectada a seguinte proporção desses aspectos: emocionais foram relatados por 8,5\% dos entrevistados; hierárquicos foram mencionados por $31,7 \%$ dos entrevistados e, trabalho foi respondido por $59,8 \%$ dos informantes.

Tabela 2

Pessoas consideradas representativas para UFSC, sob a ótica dos entrevistados

\begin{tabular}{lcc}
\hline \multicolumn{1}{c}{ Pessoa mensionada } & Frequência absoluta & Frequência Relativa \\
\hline Reitor & 22 & 11,1 \\
Roselane Neckel & 16 & 8,0 \\
Caspar Erich Stemmer & 12 & 6,0 \\
João David Ferreira Lima & 11 & 5,5 \\
Rodolfo Joaquim Pinto da Luz & 7 & 3,5 \\
TAE'S & 4 & 2,0 \\
Alunos & 3 & 1,5 \\
Chefe de Departamento & 3 & 1,5 \\
Docentes & 3 & 1,5 \\
"Eu" & 3 & 1,5 \\
Outros & 115 & 57,8 \\
\hline TOTAL & $\mathbf{1 9 9}$ & $\mathbf{1 0 0 , 0}$ \\
\hline
\end{tabular}

Fonte: dados primários..

A tabela anterior apresenta os papéis ou o nome das pessoas que mais foram citadas pelos participantes. As respostas têm relação tanto com aspectos hierárquicos quanto emocionais e de trabalho. Primeiramente a resposta com maior incidência foi Reitor quando tratado o âmbito hierárquico prioritariamente, devida a sua importância para a instituição. Em sequência são citados quatro reitores, lembrados pelos trabalhos que exerceram na instituição. Constam em sequência, em número menor de citações, servidores técnico-administrativos (TAEs), discentes e docentes, ou seja, basicamente o corpo funcional da instituição e demais pessoas que interagem com a instituição. Por fim, alguns entrevistados elencaram a si próprios como pessoas importantes para a UFSC.

Em sequência é apresentado as categorias identificadas pelas respostas dos participantes da pesquisa: posição hierárquica; relação emocional; relevância do trabalho.

\subsection{Categoria: posição hierárquica}

Ao pensar apenas numa perspectiva hierárquica, ou seja, quando o participante vincula uma pessoa 
importante ou representativa para a universidade tendo como ponto de vista o cargo ou função que ela ocupa, necessariamente a maior incidência foi o cargo máximo da instituição - Reitor (21 respondentes); seguido pela reitora Roselane Neckel (4 respostas), e Chefe de Departamento com 3 respostas.

Algumas das justificativas dos participantes sobre sua escolha foram: “[...] porque representa institucionalmente a UFSC e a lidera, imprimindo ritmo de trabalho e definindo os rumos" (Reitor - P16); "Dirigente máxima da IES; Por ser o administrador geral da instituição; Figura representativa máxima da Instituição" (Reitor - P19; P48; P51); "Suas escolhas políticas e administrativas afetam a TODOS na UFSC, então é importante (não disse que é positivo, disse importante)" (Reitor - P54); "São os cargos máximos da UFSC, eleitas, representam a instituição, encaminham decisões importantes para o rumo desta instituição" (Reitor - P89); "Pessoa que deve cuidar da instituição nas suas finalidades como um todo, com desvelo, sem preferências ou rivalidades entre os diferentes centros. Manter a ordem, estrutura, nome e qualidade do ensino" (Reitor - P93); “A Reitora porque é a cabeça geral da UFSC. Representa a Gestão de um modo geral, que abrange o planejamento, tomada de decisões, política de funcionamento da UFSC e condução da instituição. Muita coisa depende dela e das suas articulações" (Reitor - P165); "Representante da Universidade" (Roselane Neckel - P42); "Como uma profissional importante para a instituição, uma vez que ocupa o cargo de reitora" (Roselane Neckel - P194).

Dentro da instituição a figura mais conhecida é o(a) reitor(a), e é ele ou ela que está à frente da instituição por determinado tempo. E necessariamente a Reitoria, órgão executivo máximo da instituição, tem por competência, segundo o Art. $3^{\circ}$ do Regimento da Reitoria (UFSC, 2012, p. 1), "[...] planejar, organizar, dirigir, coordenar e controlar todas as atividades da Universidade."

E neste mesmo regimento, o Art. $6^{\circ}$ apresenta as competências do Reitor, que inclui, em especial no inciso I - "representar e administrar a Universidade, bem como superintender, coordenar e fiscalizar todas as suas atividades" (UFSC, 2012, p. 2). As justificativas dos pesquisados vai no sentido do trabalho que é exercido e incumbido ao reitor, e obviamente a sua importância para a organização.

O ocupante do cargo de reitor, como um gestor/líder maior, deve além de suas obrigações estabelecidas em regimento, reforçar os valores da cultura da instituição, representar o que ela defende, e motivar os integrantes da mesma. É o cargo com maior representatividade para a instituição e seus colaboradores, o que denota maior destaque a atenção para os seus comportamentos e ações.

Por fim, como os colaboradores observam os seus líderes, a identificação da liderança por um traço hierárquico é algo que se manifesta de forma natural ao longo do tempo, podendo se transformar também num aspecto emocional e relacionado ao trabalho desenvolvido pelo ocupante dessa função.

\subsection{Categoria: relação emocional}

Na relação emocional para escolha de determinada pessoa como importante ou representativa para a UFSC, é destacado o vínculo emocional das escolhas dos pesquisados. Neste aspecto, muitos nomes de servidores foram citados, inclusive os próprios respondentes da pesquisa se auto "elegeram". As falas dos entrevistados evidenciam associação entre a categoria "relação emocional" e a categoria "posição hierárquica", pela presença de manifestações emocionais de auto-apreço e identificação vinculadas à figura do ocupante do cargo de reitor(a).

Algumas das verbalizações identificadas pelos participantes foram: "Acredito que como mulheres, romperam e continuam rompendo barreiras na UFSC" (Roselane Neckel \{Reitora\} e Lúcia Helena Pacheco 
\{Vice-reitora\} - P64); "Sei que já escrevi minha história na UFSC e sei que vou deixar meu legado, pois ao longo desses anos sempre me dediquei $100 \%$ ao meu trabalho pra devolver o melhor pra sociedade que me paga" ("Eu" - P7); "Eu me considero importante, pois sei da minha busca por fazer mais e melhor para a comunidade universitária" ("Eu" - P87); "Porque participei do grupo de assédio moral há cerca de dois anos e ela me ensinou algo pra vida muito importante: 'o assediado tem que tomar muito cuidado para não começar a agir como quem o assedia, tendo um comportamento semelhante com os demais [...]"' (Suzana da Rosa Tolfo $-\mathrm{P} 164)$.

O discurso do P64 também reflete outros participantes (P59, P137, P161 e demais), sobre a ex-reitora Roselane Neckel (e também a vice-reitora, Lúcia Pacheco) como as primeiras mulheres ocupar o cargo de reitoras na UFSC. Em um cargo até então masculino, o surgimento de duas mulheres no poder da instituição trouxe consigo um debate de gênero, que ao longo de sua gestão algumas vezes foi associado a críticas sobre o trabalho e a capacidade de ambas pelo fato de serem mulheres.

Segundo Freitas (2001), há pouco tempo, quanto mais uma mulher era bem-sucedida no trabalho, mais era malvista e caluniada. Apesar da ampliação e aceitação de mudanças por muitos, esta visão não desapareceu completamente, uma vez que continuamos vivendo em uma sociedade machista, não essencialmente como uma mentalidade exclusiva masculina (Freitas, 2001). Hirigoyen (2006) complementa e enfatiza que no ambiente organizacional não se fala em igualdade de sexo, sobretudo quando se sobe na hierarquia, pois para muitos as mulheres não estão aptas a postos de responsabilidades.

Alguns participantes destacaram a si próprios como importantes para a instituição, pelo trabalho que desenvolveram/desenvolvem, pelo seu comprometimento com a UFSC e com a própria comunidade. Ou seja, para esses é possível pensar que não há heróis nessa cultura, mas há contribuição individual, que é singular para compor a cultura.

Outro discurso a ser destacado é o do Pesquisado 164 que retrata sobre sua participação em um grupo de apoio psicológico a vítimas de assédio moral, o qual segundo ele(a) foi ajudado(a) a compreender melhor a violência e não replicá-la com os demais colegas de trabalho, o que contribui para pensar na importância de ações com vistas a dar assistência aos que sofrem com o assédio moral no trabalho. Não raro, a vítima de assédio moral pode se tornar um(a) agressor(a), como em situações onde vivencia tratamentos hostis de seu superior, e passa a replicá-las com seu(s) subordinado(s) (Hirigoyen, 2006). Aquele que luta com monstros deve acautelar-se para não se tornar também um monstro (Nietzsche, 2005).

Nesta categoria, o vínculo perpassa o aspecto formal do trabalho ou hierárquico, entra num espaço mais profundo das relações e sentimentos dos participantes. Os gatilhos para a manifestação de tal ligação mais densa foram tanto por ocasião de uma quebra do status quo, que promoveu novas e desejadas mudanças, quanto pela ocorrência de algum suporte afetivo-emocional em momento de maior fragilidade ou problema.

\subsection{Categoria: relevância do trabalho}

$\mathrm{Na}$ última perspectiva, relacionada ao trabalho, os pesquisados apresentam pessoas que entendem como significativas devido a importância do seu trabalho na instituição. Consequentemente, a história da UFSC, conforme já mencionado, tem como figuras centrais os reitores que representam ou representaram a instituição. Neste sentido, os mais citados foram os ex-reitores, Caspar Erich Stemmer (12), João David Ferreira Lima (11), Roselane Neckel (8), Rodolfo Joaquim Pinto da Luz (7).

Algumas das verbalizações identificadas foram: “[...] foi o grande transformador da UFSC no seu in- 
centivo a Pós-graduação e crescimento físico do Campus” (Caspar Erich Stemmer - P22); “[...] um visionário, e que efetivamente se mobilizou para elevar a instituição a níveis de excelência internacionais, sem perder a noção prática do processo" (Caspar Erich Stemmer - P44); "O primeiro Reitor da UFSC, Prof. João David Ferreira Lima, por história de construção da UFSC, vivenciada pelo meu Pai, já falecido, que muito relatou o orgulho de vivido esse momento com o referido professor” (João David Ferreira Lima - P49); “[...] pelo pioneirismo, empreendedorismo e compromisso com a construção do bem público. Agentes de Alavancagem institucional diante da sociedade nacional e do sistema mundo" (João David Ferreira Lima - P148); "Reitor por duas vezes, incentivou a PG e inseriu a UFSC no cenário nacional e internacional" (Rodolfo Joaquim Pinto da Luz - P103); "Reitor que auxiliou na expansão da UFSC (edificações e início da expansão dos campi)" (Rodolfo Joaquim Pinto da Luz - P143); "Faz uma grande gestão, mas nada num mar de tubarões famintos e impiedosos. Está de mãos atadas e mesmo assim, tem conseguido articular importantes mudanças” (Roselane Neckel - P75); “[...] pela coragem de assumir decisões antes nunca tomadas na gestão da UFSC. Não estou julgando o teor de suas decisões e sim sua coragem" (Roselane Neckel - P95).

João David Ferreira Lima foi o primeiro reitor da UFSC e, naturalmente é uma das pessoas mais notórias na história da instituição por ter feito parte da sua construção e luta pela universidade. Em sequência, Caspar Erich Stemmer, terceiro reitor da UFSC, é lembrado pelo incentivo de professores em Dedicação Exclusiva, expansão do campus, formação de professores e por sua postura austera na instituição. Já Rodolfo Joaquim Pinto da Luz, foi reitor da UFSC em três momentos, e teve importância no crescimento/expansão da UFSC e a projeção da instituição no âmbito nacional e internacional. Por outro lado, os argumentos dos pesquisados com relação a atual reitora, Roselane Neckel, estão enaltecendo o trabalho que ela e a sua vice (Lucia Pacheco) desenvolveram para mudar a cultura da universidade. Some-se a isso a atualidade da gestão de ambas e o fato de serem as primeiras mulheres a ocupar o cargo de reitoras na instituição em estudo.

Outras respostas apresentadas pelos participantes giram em torno de enaltecer os integrantes da instituição de forma geral. Ou seja, para alguns "todas as pessoas são importantes para a UFSC" (P151; P213). E, na mesma direção (P174), considera “[...]importante todas as pessoas que 'vestem a camisa da UFSC', ou seja, se preocupam com a qualidade do seu trabalho [...]". Outra resposta a se destacar foi a do Pesquisado 34, que segundo ele "As pessoas vão e a UFSC fica. Alguns fazem a diferença, mas no final das contas sobra a UFSC e as pessoas, importantes ou não, acabam passando".

Segundo Freitas (2007) as pessoas significativas, ou heróis momentâneos, sempre existirão nas organizações, pois são aquelas pessoas que ultrapassam as metas, que desenvolvem os melhores projetos, que exercem suas atividades de forma produtiva. Porém, a lógica é que as pessoas passam, e a organização permanece. Ou seja, os heróis são circunstanciais e não simbolizam a organização permanentemente, visto que podem ser superados ou esquecidos. Contudo, na pesquisa, isso não se sobressai quando apresentado em uma perspectiva hierárquica e de trabalho, pois nestes casos, foram identificados reitores tanto atuais quanto antigos da instituição.

Por fim, independentemente dos nomes elencados, seja por uma questão hierárquica/cargo, vínculo emocional, ou relacionado ao trabalho desenvolvido, o fato é que o reconhecimento da liderança advém de algum tipo de influência (negativa ou positiva) sobre os colaboradores, que acabam por compor a cultura da organização. Alguns com maior poder de influência, outros na replicação dos valores e costumes estabelecidos ao longo da história. E tais situações muitas vezes não estão inicialmente visíveis para aqueles que ingressam na UFSC, mas ao vivenciarem o trabalho, a imagem que tinham sobre a instituição se distorce - conforme se 
pode observar na próxima seção.

\section{Considerações finais}

A liderança no ensino superior é inevitável para que a formação do indivíduo e a aprendizagem aconteçam. Portanto, estudar esse tema é contribuir para que uma educação efetiva seja erigida e possa fazer parte de modo positivo no desenvolvimento da cultura de um país.

Diante da análise de conteúdo das 214 respostas obtidas, conclui-se que são fatores críticos para o reconhecimento da liderança (ou de um líder): posição hierárquica ou cargo, vínculo emocional, e reconhecimento do trabalho desenvolvido. Esses três elementos foram identificados como os que mais inspiram os colaboradores e moldam a identidade e os valores da instituição.

Tais fatores influenciam tanto negativa quanto positivamente a cultura de organização e fazem parte de sua história, bem como compõem a construção de seu futuro. Algumas pessoas foram identificadas com maior grau de influência, outras contribuíram para a replicação de valores e costumes estabelecidos ao longo da existência da instituição.

Muitas vezes esses aspectos não estão inicialmente visíveis para aqueles servidores que recém ingressam na UFSC. Todavia, ao vivenciarem o trabalho, ao conviver com os diferentes indivíduos e grupos, a imagem que tinham sobre a instituição acaba por se modificar. Tal mudança é uma consequência do próprio envolvimento com as pessoas e a cultura organizacional e, indica o grau de influência que o grupo pode exercer sobre o indivíduo, ou ainda, que a instituição exerce sobre o colaborador.

Este estudo permite compreender a interconexão existente entre a relação emocional despertada pela identificação com o ocupante de um cargo significativo na hierarquia da instituição. Tal fenômeno de projeção e reconhecimento de si mesmo em um outro com mais poder e influência merece ser futuramente investigado, pode ser uma forma de autovalorização, motivação, ou uma forma de criar sentido no trabalho. Do mesmo modo, a tônica de enxergar a si mesmo como importante para a instituição sugere uma forma peculiar e emergente de compreender o fenômeno da liderança em si, dissociada de cargos e hierarquia e vinculada a aspectos mais subjetivos e práticos, que evocam sutilezas como sentimento de pertencimento e autopercepção de contribuição.

Assim, conclui-se que características como escuta, comunicação, capacidade de adaptação, de reflexão e de estímulo ao aprendizado, bem como o direcionamento à formação de consensos e à negociação estão presentes nas pessoas que foram lembradas pelos servidores como referência de liderança. Futuramente, sugere-se estudos que se debrucem mais profundamente sobre o desenvolvimento e a manifestação de tais características pelos líderes, sobre a percepção dessas características pelos liderados e sobre a formação da cultura organizacional pautada no reconhecimento de pessoas específicas como líderes influentes em sua história.

\section{Referências}

Altbach, P. G., \& Salmi. J. (2011) The Road to Academic Excellence: the making of worldclass research universities. Washington: The World Bank. (Acessed May 2018). http://documents.worldbank.org/curated/ pt/688061468337210820/pdf/646680PUB0acad00Box361543B00PUBLIC0.pdf

Bertoncini, I., \& Cunha, C. J. C. A. (2017). Liderança no setor público brasileiro: o estado da arte. Anais do I Congresso Internacional de Desempenho do Setor Público (CIDESP). Florianópolis. 1765-1777. (Acessed 
May 2018). http://cidesp.com.br/index.php/Icidesp/1cidesp/paper/view/101/94

Bardin, L. (2011). Análise de conteúdo. Ed. rev e ampl. São Paulo: Edições 70.

Bolman, L. G., \& Deal, T. E. (1995) Organización y liderazgo: el arte de la decisión. Buenos Aires: Addison Wesley Iberoamericana.

Brasil (2014). Tribunal de Contas da União. Referencial básico de governança: aplicável a órgãos e entidades da administração pública / Tribunal de Contas da União. 2 a versão. Brasília: TCU, Secretaria de Planejamento, Governança e Gestão. (Acessed June 2018). https://portal.tcu.gov.br/lumis/portal/file/fileDownload. jsp?fileId=8A8182A14DDA8CE1014DDFC35CA83C74

Brasil (2012). Resolução $\mathrm{n}^{\circ}$ 466, 12 de dezembro de 2012. Dispõe sobre as diretrizes e as normas regulamentadoras de pesquisa envolvendo seres humanos. Conselho Nacional de Saúde. Brasília. (Acessed June 2017). http://conselho.saude.gov.br/resolucoes/2012/Reso466.pdf

Burrel, G., \& Morgan, G. (1979). Sociological paradigms and organizational analysis. London: Helnemann Educational Books.

Daft, R. (2000). Administração. Rio de Janeiro: LTC.

Fonseca, A. M. O., Porto, J. B., \& Borges-Andrade, J. E. (2015). Liderança: Um Retrato da Produção Científica Brasileira. Revista de Administração Contemporânea - RAC. 19(3), 290-310. (Accessed May 2018). https:// dx.doi.org/10.1590/1982-7849rac20151404

Freitas, M. E. (2001). Assédio Moral e Assédio Sexual: faces do poder perverso nas organizações. Revista de Administração de Empresas -RAE. 41(2), 8-19.

Freitas, M. E. (2007). Cultura Organizacional: evolução e crítica. São Paulo: Thomson Learning.

Freitas Jr., J. C. S., Klein, A. Z., \& Fargundes, P. M. (2015). Uma Proposta de Instrumento Quanti-Qualitativo para Autoavaliação de Competências de Liderança. Revista de Administração da Unimep. 13(3), 1-27.

Fleury, A., \& Fleury, M. (2004). Estratégias empresariais e formação de competências: um quebra cabeça caleidoscópico da indústria brasileira. São Paulo: Atlas.

Hirigoyen, M-F. (2006). Mal-estar no trabalho: redefinindo o assédio moral. 3. ed. Rio de Janeiro: Bertrand Brasil.

Lorenzo, M. (2005). El liderazgo en las organizaciones educativas: revisión y perspectivas actuales. Revista española de pedagogia. LXIII (232), 367-388. 
Minayo, M. C. S. (Org.) (1994). Pesquisa social: teoria, método e criatividade. Rio de Janeiro: Vozes.

Nietzsche, F. W. (2005). Além do bem e do mal: prelúdio a uma filosofia do futuro. São Paulo: Companhia das Letras.

Nunes, T. S. (2016). A influência da cultura organizacional na ocorrência do assédio moral no trabalho na Universidade Federal de Santa Catarina. 2016. 432p. Tese (Doutorado) - Universidade Federal de Santa Catarina, Centro Socioeconômico, Programa de Pós-Graduação em Administração, Florianópolis.

Nunes, T. S., Tolfo, S. R., \& Garcia, I. S. (2018). Valores organizacionais declarados e praticados na Universidade Federal de Santa Catarina. Administração Pública e Gestão Social. 10(2), 123 - 135. (Accessed Dez 2018): https://doi.org/10.21118/apgs.v10i2.1566

Ortiz, C. M. A. (2017). Ventajas del liderazgo distribuido en instituciones de educación superior. Revista Iberoamericana para la Investigación y el Desarrollo Educativo. 8(15), 817-832. (Accessed May 2018). https:// dx.doi.org/10.23913/ride.v8i15.322

Reis, F. J. G. (2010). Formação de líderes para gestão e universidade de classe mundial. (Accessed May 2018). http://www.fabiogarciareis.com.br/documentos/UniversidadedeClasseMundial.pdf

Robbins, S. P. (2005). Comportamento organizacional. 11.ed. São Paulo: Pearson/Prentice Hall.

Romero, V. R., Cázares, M. C., \& Barrera, C. T. El liderazgo directivo y la gestión en el nivel medio superior del Instituto Politécnico Nacional de México: una mirada desde los estudiantes. Revista Iberoamericana para la Investigación y el Desarrollo Educativo. 8(15), 81-115. (Accessed May 2018). https://dx.doi.org/10.23913/ ride.v8i15.292

Richardson, R. (2008). Pesquisa Social: métodos e técnicas. 3. ed. São Paulo: Atlas.

Vergara, S. C., \& Caldas, M. P. (2005). Paradigma Interpretacionista: a busca da superação do objetivismo funcionalista nos anos 1980 e 1990. RAE-Revista de Administração de Empresas. 45(4), 66-71.

UFSC. Universidade Federal de Santa Catarina. (2012). Regimento da Reitoria. Aprova o novo Regimento da Reitoria e altera o nome da Secretaria Especial de Aperfeiçoamento Institucional. Resolução normativa ${ }^{\circ}$ 28/CUn, de 27 de novembro de 2012. Lex: Coletânea de Legislação e Jurisprudência. Florianópolis, p. 1-19, 2012. (Accessed October 2015). http://portal.reitoria.ufsc.br/files/2014/01/Regimento_Reitoria.pdf 